\title{
Conflicting duties and restitution of the trusting relationship
}

\author{
Andreas Eriksen
}

\begin{abstract}
It is often claimed that medical professionals are subject to conflicting duties in their role morality. Some hold that the overridden duty taints the professional and generates a patient claim to a form of moral compensation. This paper challenges such a 'compensation view' of conflict and argues that it misleadingly makes the role morality into a personal contract between professional and patient. Two competing views are therefore considered. The 'unity view' argues that there are no real conflicts between professional duties. Hence, there can be no residual duties that are impossible to discharge and no special claim on the part of the patient. It is argued that this fails because the institutional nature of the role morality requires us to accept possibility of conflict. The paper articulates and defends a third view, where conflict triggers a professional duty of restitution. This duty is not a matter of making amends for a previous wrong, but rather a matter of rebuilding a trusting relationship that has been damaged due to blameless circumstances.
\end{abstract}

http://dx.doi.org/10.1136/medethics-2017-104682

\section{Introduction}

Professionals constantly face hard cases in their interaction with patients, colleagues and the public. They are torn between different considerations and exposed to seemingly incompatible expectations from their surroundings. Doctors find that their duty to respect patient autonomy can appear contrary to their duty of beneficence. A nurse might experience it difficult to exercise duties of care and concern in a way that respects considerations of comparative fairness between her patients. Medical researchers sometimes see their duty to scientific progress as in tension with the duty to respect human life.

Part of being a good professional is to aim at finding the best solution in such circumstances. It is a central professional task to make coherent and justifiable decisions. However, some believe that finding the best solution in a given situation can still leave professionals 'morally tainted'-their hands get 'dirty' no matter what they do and this calls for a special form of regret. But although terms like taint and regret may resonate with moral phenomenology, they are vague with regards to the actual normative status of the action in question. Can professionals really be bound by conflicting duties in a way that condemns them to blameworthiness? This paper challenges that idea.

\section{The institutional nature of professional role morality}

This discussion requires a preliminary account of professional duties. They are 'institutional' in the sense that they are created through procedures and practices that generate a collective recognition of what counts as wrong in the medical context. ${ }^{1}$ However, the institutional nature of professional role morality should not be taken to imply that it has a fully formal or rule-based character. The collective recognition of professional role morality comprises expectations of certain complex attitudes, such as care, loyalty and respect. The broad duty of concern for the patient cannot be codified to deliver determinate behavioural constraints. The professional has a duty of fidelity to the patient that requires careful interpretation of the circumstances.

The institutional nature of professional role morality is an important source of experiences of conflicts between duties. This is perhaps most easily seen in cases where the duty of concern for the particular patient requires actions that go against the interest in upholding certain publicly accessible standards. For example, Torbjörn Tännsjö discusses the real-life case of a Jehovah's Witness who asks to forgo life-saving blood transfusion, where it is obvious that the request is due to inappropriate social pressure. ${ }^{2}$ She has just given birth and has expressed a will to receive blood, 
but the elders of her congregation are allowed in the hospital room to advise her against receiving the vital help. On Tännsjö's account, the doctor is morally required to give blood transfusion in secret, but should also accept sanctions if this is discovered. That is because sanctions may be necessary in order to uphold public trust in the institution.

Here, one could argue that the doctor is adequately responsive to the duty of concern for the patient and that the sanctions are instrumental to upholding a public commitment to patient autonomy rather than a genuinely penal reaction to wrong against the particular patient. Nevertheless, the sanctions are not thereby reducible to a public façade disconnected from genuine role morality. In order to act in the name of their institutional practice, role holders must reason from a public deliberative framework. Upholding public trust is an integral part of this framework, but we trust professionals both to have concern for our fate and to comply with transparent standards for making decisions in this regard; there is therefore a latent tension within the role morality.

The focus here is on what a conflict of duties entails in moral terms for the ongoing relationship. Are patients wronged in such scenarios of conflict? Is there a real conflict? And what does the profession owe the patient? This paper delineates and discusses three models. The 'compensation view' argues that the overridden duty persists and taints the professional in a way that grounds a patient right to moral compensation. The 'unity view' argues that the appearance of genuine conflict is illusory and there can be no special claims on the part of the patient. I argue that none of these views captures the normative situation adequately. The suggestion is that the 'restitution view' can give a better account because it allows for a morally significant form of conflict of professional duties and yet does not see the overridden duty as giving rise to compensation. Instead, conflicts trigger a duty of restitution that involves rebuilding the relation. Those who represent the profession need to re-establish the trusting relation in order to care for and respect the patient.

I will be seeing the ongoing relationship between a medical professional and a patient as paradigmatic, but that does not imply that a conflict of duties cannot change the normative situation of several professionals or involve claims by third parties. In some cases, it will be most appropriate that a new representative of the profession continues the contact with patient. However, the situation can nevertheless remain structurally similar because the patient still relates to the same kind of bearer of a role morality (insofar as the original professional acted legitimately). The issue of third-party members of the public, on the other hand, involves further complications that I cannot deal adequately with here. For example, given the peculiarities of the Jehovah's Witness situation, perhaps it is more likely that some of the elders of the congregation (rather than the patient herself) feel that the professional has violated a trusting relation between the profession and the public. As members of the public to which the profession has made a commitment, third parties may engage as potential future patients and as guardians of the public standards of professional role morality. This raises some further issues regarding how we determine the vicarious 'standing' to hold each other accountable (ie, the ethics of 'minding your own business'). 4

\section{The compensation view}

In their highly influential book Principles of Biomedical Ethics,, Tom L. Beauchamp and James F. Childress discuss conflicting obligations. Their discussion starts by noting how some obligations are 'prima facie', meaning that they bind 'unless a competing obligation outweighs it in a particular circumstance' (Beauchamp and Childress, p15). Their main example is a psychiatrist who has confidential medical information about a patient who is also an employee at the hospital where the psychiatrist works. What should the psychiatrist do when this patient (and colleague) is seeking advancement in a stress-filled position? According to the stipulation of the example, confidentiality prohibits disclosure, but beneficence requires that the psychiatrist protect both the patient and the hospital. Beauchamp and Childress mention further conflicting prima facie duties in this case, and 
they state that the psychiatrist must deliberate to establish his 'actual' obligation in the circumstances.

Let us suppose that the psychiatrist permissibly chooses to disclose the confidential information to the hospital administrator. Importantly, this is not intended to support any first-order judgment about the case; nothing in my argument hinges on the substantive conditions of confidentiality. The question is what happens to the overridden prima facie of duty confidentiality. Beauchamp and Childress argue that even the agent who chooses the best option under the circumstances may not be able to discharge all duties: 'The point is about continuing obligation, not merely about feelings of regret and residue. Moral residue results because an overridden prima facie obligation does not simply go away when overridden'(Beauchamp and Childress, p16) ${ }^{5}$. It follows from this that the psychiatrist who finds it necessary to inform the hospital administrator is still bound by the duty of confidentiality as it applied to this situation. The patient's right to confidentiality has allegedly not been satisfied, even though it would have been wrong not to disclose the information to the hospital administrator. As Beauchamp and Childress say in the quote, this is a claim about what one genuinely owes others, not just a psychological reaction due to the discomfort of letting someone down.

In one sense, it is obviously plausible to say that the overridden duty does not simply disappear because being overridden does not mean being invalidated or cancelled. ${ }^{6}$ The psychiatrist is still bound by confidentiality qua professional in his future activity, so the 'continuing duty' account is credible yet trivial if understood in this way. However, this is not the kind of continuation of duty that Beauchamp and Childress have in mind. Even in cases where the role holder chose the best available action (ie, discharged the 'actual obligation'), they speak of the agent 'failing' to perform the overridden duty and of the failure as generating a call for 'compensation' to those who were wronged (Beauchamp and Childress, p16).. . It therefore seems as if circumstances can make a role holder blameworthy no matter what action is taken.

Note that we cannot help ourselves to the principle of 'ought implies can' in criticising this view. That would lead to a kind of 'exoneration view', where the idea is that the professional did something wrong but the inescapability of wrongdoing absolves the professional of blame. That is, the psychiatrist would supposedly have an excuse because he was trapped by the conflict of duties. On this modified view, the psychiatrist is not tainted by the breach of confidentiality because the circumstances gave him no other option. This view is appealing because excuses tend to acknowledge the experience of the aggrieved; it was a bad thing that happened. The function of excuses is to explain why the bad thing should not be taken to imply blameworthiness on the part of the agent. Unlike apologies that call for forgiveness, excuses aim to explain that there is nothing to forgive because the agent did not act wrongly.

But this will not work in our case. The psychiatrist is not really a victim of circumstances. He needs to speak on behalf of his profession; his role cannot be separated from the institution he represents. Perhaps an excuse could exonerate him qua private person; 'My profession is sadly incoherent in the way it invites the public to trust in conflicting role requirements, but that is not something I could prevent.' Even if that were acceptable to the patient, it is not the kind of shield from blame we are searching for. We want to know what should be done in the name of the profession.

The problem with the compensation view is not the unfairness of condemning professionals to blameworthiness, but rather the misguided rights attributed to the patients involved. The idea that patients have a claim to some kind of compensation in conflict scenarios falsely assumes that professional role morality is akin to a personal contract. Someone who makes a contract with a service provider may indeed have a right to compensation if the terms are not met, even if the reason for the failure to deliver was that the service provider wanted to promote some greater good. However, insofar as we want to see professional role morality as a contract, it is a contract between the profession and the public. Patients have a right to compensation if they suffer from 
professional decisions that fail to express fidelity to this contract. The fact that a patient experiences that a duty of confidentiality was overridden does not mean that the role holder has been unfaithful to the contract with the public. It is rather the contract itself that dictates that confidentiality shall not be kept at all costs but is subject to certain constraints grounded in the safety of third parties.

However, if there is no genuine basis for compensation in these cases, can we really accept the reality of conflict? The next section discusses a view that asks us to question the idea that professions really generate conflicting duties. On this account, the patient's grievance is allegedly unwarranted because the duty of confidentiality, when properly interpreted, did not apply. This has the advantage of avoiding the paradoxical idea of professionals doing the right thing but still having to compensate for wrongdoing. Do we have reason to reject the appearance of conflict?

\section{The unity view}

The idea of unity of moral requirements can take many forms, but Ronald Dworkin's Justice for Hedgehogs is an extensive defence that is particularly relevant for our purposes. ${ }^{7}$ While the book does not discuss the status of professional duties as such, some of its main ideas can be used to construct an account of unity in professional ethics. Indeed, some important examples in his book are from the professional context. Nevertheless, it should be emphasised that the 'unity view' as presented in this paper merely draws on insights from Dworkin; the model of professional duties should not be attributed to his work.

A central case in Dworkin's argument for the unity of moral requirements is an academic torn between expectations of honesty and kindness: 'A colleague asks you to comment on a draft of his book, and you find it bad. You will be cruel if you are frank but dishonest if you are not' (Dworkin $\mathrm{R}, \mathrm{p} 188) .^{7}$ Dworkin uses this description of the case to illustrate the kind of conflict view he opposes. The key thesis of the book is that we should not take such appearances of conflict as final; the experience of incompatibility of moral requirements will often be resolvable by rethinking how these requirements are open to interpretation and grounded in mutually supporting considerations. A more nuanced interpretation of honesty and kindness, for example, may reveal that kindness is compatible with being frank in this setting (or perhaps the contrary conclusion that honesty does not require disclosure of one's personal opinion in this case).

The unity view rejects the idea that these hard cases require 'weighting' in the sense that one adopts priorities for some discrete duties to the disfavour of others. Rather, the more ambitious claim is that the duties cohere in a way that implies that one does not have to choose among them. If one decides that frank comments are the most morally responsible reaction in the example, then one is not deciding against the requirement of kindness or giving it a lower priority. Instead, one is acting on the judgment that kindness does not require self-censorship in such circumstances.

Of key importance here is the idea that we cannot treat moral requirements as having isolated justifications. Understanding one moral requirement requires interpreting how it supports and is supported by other concepts. We understand the duty of honesty in light of terms like respect, authenticity and trust, for example. These terms can in turn also be illuminated by the idea of honesty. Dworkin therefore speaks of 'simultaneous equations to be solved together'(Dworkin R, p 263). ${ }^{.}$We are never entitled to say 'that's just the way it is' with regards to moral issues, we can always be called on to give reasons when we are holding others to a moral constraint. These reasons will refer to further connected moral considerations, meaning that moral justification is ultimately a holistic enterprise. The alternative is to see morality as a heap of brute moral facts.

It can be tempting to take this to have the further implication that conflict between professional role obligations is impossible. That is, perhaps we can make sense of the various role obligations by interpreting them in light of each other. The meaning of the duty of confidentiality may depend on the meaning of further duties, like beneficence and respect for autonomy. On this reading, a 
judgment on how to protect patient information in the right way can imply also making judgments about what it means to serve health (eg, in cases of dangerous contagious diseases) or on who is competent to decide what can be made public (eg, when patients want to release their doctor from their confidentiality). As opposed to the account of Beauchamp and Childress above, this approach asks us to see the content of one duty as inherently sensitive to further obligatory considerations. The duties do not interact simply by way of having fixed content with different normative weights attached, but rather by the content of each duty being partially constitutive of the meaning of the other. How would this affect the case of the psychiatrist with a patient who applied for a position in the same hospital?

Let us imagine that the patient learns that the information has been divulged. On the unity view, the psychiatrist might try to explain how the duty of confidentiality does not require withholding information in this case. The best interpretation of the duty is not the mechanical protection of patient data no matter the consequences, but rather a form of safeguarding information in a way that is sensitive to other duties in a responsible way. In this case, the concern for the safety of other patients is among the valid concerns that must go into the understanding of confidentiality. This seems to be a more reasonable approach to the interpretation of duties in professional ethics than the one indicated by Beauchamp and Childress. But does the unity thesis have the same plausibility with regards to professional ethics as it has with regards to natural moral duties?

The institutional nature of professional role morality raises some difficulties here. No organisational procedure or public declaration can establish the general moral meaning of beneficence or respect for autonomy. Arguably, the normative force of procedures depends on some prior commitment to such moral values. By contrast, many kinds of procedures and elements of practice determine the content of professional role requirements. Profession role morality is a complex social institution where different agents (eg, professional associations, legislators, organisational boards, etc) have legitimate authority to enact rules that set more or less determinate interpretations of normative content. Professionals may be expected to comply with the abstract duties of their role morality as they have been articulated in the codes of ethics, law, organisational policies, precedents of practice, through authority relations and more.

For example, the AMA Code of Ethics speaks of the 'physicians' ethical responsibility to place patients' welfare above the physician's own self-interest or obligations to others'. We can construe this concern with patient welfare as compatible with duties to warn third parties and duties to respect patient autonomy as long as these further duties are open to interpretation. The difficulties begin when we constrict our understanding of these further duties to their actual definitions in law, organisational guidelines, etc. Perhaps an interpretive virtuoso could still make a coherent picture, but that is largely irrelevant. We need a concept of professional duties that is publicly accessible, and that means that duties cannot be taken to designate much more than what they say in isolation, their meaning cannot depend on complex interpretive procedures. That would make them opaque and insufficiently conducive of trust.

Of course, this complex web of institutionally defined duties must somehow be made sense of by role holders. Professionals are irresponsible if they simply comply with the latest instruction without sensitivity to how it fits within a broader framework that governs the professional promise to the public. That is, they need to appreciate some justificatory reasons for the duties and not simply accept them as a heap of random decisions. A prevalence of conflict of duties will create an impression of randomness and thereby threaten to undermine the assurance-serving function of professional ethics. Professionals should therefore strive to make their profession speak with one principled voice. However, the fact that unity is a warranted regulative idea for interpretation does not mean that actual harmony can be achieved among the existing duties. Sometimes even the best interpretation may leave the professional with conflicting duties. Conflict may be a good reason 
for revising the existing role morality, but the conflict is real until the appropriate institutional procedures or practices have changed the normative situation.

None of the views discussed so far gives us a satisfactory account of the status of medical professional caught between conflicting duties. The compensation view left us with a misleading conception of trusting relationship as a matter of a personal contract. The unity offered a theory of moral interpretation that dissolves superficial conflict. This gave us an improved understanding of how the abstract contents of professional duties are mutually dependent and provided an alternative to the more mechanical model of weighting isolated concerns against each other. Nevertheless, this theory of unity cannot remove the conflict of artificial duties at the level of institutionally embedded action because the content of duties has been predetermined and articulated by distinct authorities in a way that gives us no a priori guarantee of unity. We still need to know how conflict can be real while no compensation is required.

\section{The restitution view}

The compensation view registered something that the unity view threatened to undermine, namely the potential experience of grievance of patients who realise that a duty they relied on has been put aside. We can imagine the Jehovah's Witness or the psychiatric patient react to the professional decisions with confusion and a sense of deceit. While the deceit is only apparent, the experience carries normative weight in its own right. But how? In this section, I want to articulate and defend a third alternative that takes this experience seriously yet does not conceive of it as tracking wrongdoing and a right to compensation or apology. The conflict of duty triggers what I will call a duty of restitution. By this, I mean a duty to facilitate the healing of the relationship and to make it clear why trust in the profession is still warranted. Ways of discharging this duty include ensuring that the patient understands the situation, explaining the reasons for the decision, expressing solicitude and taking measures to curtail possible negative effects. Most importantly, it is about engaging with the patient to find a shared perspective and a plan to move forward. The goal is not simply to coax the patient into adopting a more positive attitude to the profession and the role holder, but rather of re-establishing a relationship based on shared reasons. The goal is to reconnect with the patient as someone with whom one acts with, not merely acts on.

It is important to keep this understanding of a duty of restitution distinct from the way the term restitution is sometimes used in legal terminology (restitutio in integrum), where it means the same as 'duty of reparation'. W. D. Ross, the moral philosopher who has influenced the terminology many use to discuss these matters of medical ethics, describes the duty of reparation as 'resting on a previous wrongful act'. ${ }^{\prime}$ However, there is no wrongful act to speak of here. Rather, on my account, the duty of restitution is a duty to acknowledge that fidelity to the broader contract with the public required acts that have damaged the relation and that trust needs to be rebuilt. Perhaps speaking of a 'duty of reconciliation' would avoid some confusion. Two considerations count against this. First, the notion of reconciliation makes it sound as if the conflict has been between parties of the relationship rather than between duties. Later, I will clarify how the notion of reconciliation fits the compensation view rather than my account. Second, reconciliation is sometimes understood to involve a sense of recognising the error of previously held beliefs. ${ }^{2}$ By contrast, the duty of restitution is often about readjusting beliefs to the new circumstances of the relation, rather than rectifying any previous errors.

The next three sections present different aspects of the restitution view. The first section explains how the duty of restitution is about re-establishing a form of equality in the relationship and not simply justifying a decision. The second section clarifies how the duty of restitution relates to patient autonomy. This prepares the ground for a clarification of how the compensation view and the restitution view have fundamentally different perspectives on how conflicts of duty change the relation between professional and patient. In particular, my argument shows how the restitution view is better suited to respect the grounds of professional integrity 


\section{Re-establishing equality}

On the face of it, the duty of restitution may seem the same as a duty of justification. Justification is about explaining the legitimacy of something one has done or will do, and that is certainly part of what the duty of restitution requires. However, the duty restitution is also about sensitivity to how even legitimate actions may be perceived as undermining trust. Merely demonstrating that one acted according the dictates of an impartial role morality fails to register how the relationship has been affected. When confidentiality is breached or an autonomous patient request is overridden, there is a sense in which the conditions of joint action or professional-patient cooperation may be harmed despite the legitimacy of the action. The patient of the psychiatrist may say, 'I understand that you did the right thing, but that does not mean that we can continue as if nothing has happened.' Future interaction is placed under the shadow of the event.

The duty of restitution responds to the fact that professional role morality has a diachronic dimension; the professional relation is not simply the application of a static set of rules and prioritisations but involves a sensitivity to how past decisions affect the meaning of future ones. The future of the trusting relationship depends on patients feeling secure that a professional obligation that was overridden will nevertheless carry sufficient normative weight in the further decision-making process. This requires that the professional can re-engage with the patient on terms that track the form of equality that is appropriate to the relation. The equality at issue here is the equality of decision-making structured by publicly justified rights and duties, as opposed to the possibly idiosyncratic personal convictions of the professional. This form of equality enables the parties to participate on mutually recognised terms. It is not that a concept of equality requires the parties should have equal influence over decisions. It is rather about making decisions in a mode governed by norms that are accepted by the public, accessible to the patient and sensitive to the particularities of the situation.

Conflicts of duty are a threat to this equality because the patient may be participating on the basis of an existing right that is overridden by the decision of the professional. A decision where one's rights were overridden by other considerations can be experienced as a matter of not being an equal in the sense just described. The patient discovers that the sphere in which one can make claims in the name of professional role morality is contingent on circumstance. There is a need to help patients regain a sense of being participants on terms of equality when conflicts of duty have led to decisions that make rights seem insecure.

\section{The relation to patient autonomy}

In some respects, the duty of restitution may seem like an offshoot of patient autonomy. That is, it may appear to be duty to engage with patients to gather their views and adjust treatment accordingly. That does not capture the duty adequately. Restituting the relationship can require that treatment proceeds with less patient autonomy or perhaps reshaping the domain of patient autonomy.

In this regard, consider what is sometimes described as the conflict between the duty to instil hope and the duty to be truthful in cancer treatment. Some believe that the concerns and fears of the moment can undermine patient autonomy and justify not telling the whole truth (this is of course contentious $^{\underline{10}}$ ). Imagine, then, that a physician is torn concerning whether to give a patient with cancer with generally good prognosis some bad news. The physician knows this is most likely a minor setback, but does not know how the patient will react. The physician decides to give all the information, resulting in the patient reacting destructively and wanting to end the necessary treatment (now falsely perceived to be futile).

By hypothesis, the physician has correctly assessed that patient autonomy legitimately overrides conceivable benefits of not disclosing full information. The reaction of the patient shows that the conflict was real; there was a cost in terms of effective treatment. In this situation, creating a space 
for communication of expectations can be a way for the physician to understand how the patient conceptualises challenges to their common task. How can minor setbacks be conveyed without destroying cooperation in treatment? It is not necessarily a tool for giving more autonomy to the patient, but a process of learning what it takes for patient autonomy to be meaningful. As Eric J. Cassell notes:

The truth of the information is only one of its aspects. Of importance also are accuracy, reliability, and completeness, the meaning to the patient of the information, its relevance to the patient's problems, whether it increases or decreases uncertainty, what it indicates about appropriate or possible action, and what impact it has on the relation between patient and physician..$^{11}$

The message is that it is irresponsible of physicians to be a medium of unfiltered truth to patients. Part of being a good physician is learning and developing the "conversational implicatures" 12 of the relationship with the patient. That is, statements are taken to mean something beyond their literal meaning, and the physician-patient relationship depends on a shared sense of what the implicatures are. For example, giving much information about some development may suggest that it is important. Similarly, the absence of qualifiers suggests that the physician has strong evidence. These implicatures are governed by general standards of cooperative communication, but their precise meaning can be highly context-sensitive. A patient who has been deeply sceptical of treatment and ready to give up may take the physician's message of a setback differently than someone who has been persistently optimistic.

A duty of restitution will often involve recalibrating the implicatures of the relationship. For example, the physician may learn that giving large doses of accurate information about minor setbacks, while just giving short and vague statements about progress, generates the misleading implicature that medical science gives a bad prognosis of recovery. In the case of the patient who wanted to end treatment because of the minor setback, the conflict between patient autonomy and beneficence was created in part because the parties to the communication were not sufficiently attuned to each other. In this sense, conflicts of duty are potent triggers of a need to recalibrate the implicatures.

Some would perhaps claim that there was no real conflict here; it was rather just a failure of the physician to anticipate the patient reaction. For example, the unity view would hold that the physician could have respected both patient autonomy and beneficence by conveying the information in suitable terms in the first place. This presupposes that genuine conflicts of duty would be only those that survive to circumstances when professionals have complete knowledge and are perfectly rational. That is not a very helpful premise. Many of the most relevant and interesting conflicts of duty arise from the inherent uncertainties and idiosyncrasies of each relationship. Conflicts of duties will to some extent be a function of the mutual opacity of the agents involved. There is a genuine conflict between patient autonomy and beneficence partly because (not despite that) the physician cannot know how the patient will react and how information will be understood. These are the circumstances that determine the merits of decisions. A decision to let one duty override another is not legitimate only when the physician can be certain that it is for the best. The criterion of legitimacy is rather that the decision was appropriately responsive to the available facts of the situation. The reaction of the patient may then provide a new salient fact to which future decisions must take into account.

\section{Integrity and the distinction between mistake and betrayal}

This connection between conflicts of duty and lack of professional insight into patient reactions may appear to force us to make concessions to the compensation view. As we saw, the compensation view holds that acknowledging that a duty was overridden means that the physician is morally tainted and that some admission recognition of wrongdoing is required. In line with this, 
the focus on restituting the relationship through a process of mutual learning may seem incomplete without the notion of apology or recognition of having failed to discharge a duty.

However, this would not be a supplement to the duty of restitution, but rather a way of undermining it. This becomes clear when we consider what it is to wrong a patient. Apart from technical incompetence, a physician wrongs a patient by acting on reasons that do not respect the fiduciary nature of the professional role (ie, when the professional betrays the trusting relationship). Making conflict of duties into a matter of betraying the patient acknowledges the patient's experience of disappointment in the wrong way; it frames it as a conflict between patient and physician.

Naturally, the point here is not that the duty of restitution requires that medical professionals stay clear of admitting mistakes and apologising for misunderstandings. The duty of restitution may indeed require rebuilding the relation based on a shared view of the shortcomings of earlier decisions by the professional. However, there is an important difference between decisions that are inadequate despite responsible deliberation and decisions that are flawed because they express a betrayal of trust. The duty of restitution can be a response to an understandable mistake, but it does not seek to rectify a blameworthy betrayal. Recognising that one has acted in contempt of the trusting relationship requires something substantively different than mere learning from mistakes. Clearly, Beauchamp and Childress' talk of compensatory actions that are a response to 'deep regret and a sting of conscience' (Beauchamp and Childress, p16) relation has been betrayed.

Professionals are in a sense lacking in integrity if they have the latter reaction to their own decision that one duty legitimately overrides another. It reveals a lack of the kind of resolve that is characteristic of agents who can 'stand for something. ${ }^{13}$ Experiencing regret and stings of conscience signals that one is not sufficiently committed to the decision one has made. Part of what it means to have professional integrity is to have well-placed trust in one's own capacities. ${ }^{14}$ Professionals of integrity have the appropriate regard for their own judgment; they let responsible decisions lead to settled convictions. That does not preclude having feelings of empathy with those who suffer in some way from the decision, but the normative content of that emotion is different from a compensatory attitude guided by deep regret. The compensatory attitude distances itself from the decision. The agent is no longer fully responsive to the reasons that led to the original decision. However, in cases of conflicts of duty, integrity prohibits the agent from renouncing the reasons that led to the right decision. To renounce them would be a split in the commitments of the role holder, which is not conducive to restituting a relationship with the patient. Restituting the relationship with the patient based on shared reasons requires standing for the decision insofar as it was responsible.

\section{Conclusion}

This paper has attempted to clarify the normative situation of medical professionals who are faced with conflicting duties. Three models have been explored. The compensation view saw professionals as morally tainted by the overridden duty. The patient was conceived of as wronged by the failure of the professional to discharge the duty. The importance of this view is that it highlights an experience of disappointment on the part of patients that cannot be ignored by professional role morality. However, the problem with the compensation view is that it sees professional role morality as constituted by a personal contract. In reality, the duties of the professional are a package owed to the public. Patients are wronged when they suffer from decisions that are disloyal to values of the profession. But the responsible decision to discharge the overriding duty in cases of conflict is not a betrayal of the fiduciary relation.

The unity view saw conflict as illusory because duties require interpretation and the best interpretive approach is to see them as a mutually supportive network of considerations. This view is important 
because it takes us beyond the mechanical application of duties and the view has great plausibility with regards to 'basic duties' or general professional principles. However, it goes too far in supposing there can never be genuine conflicts. Professional duties are created through procedures that may generate conflicting outcomes given that the duties must be publicly accessible; their meaning cannot depend on complex interpretive exercises.

The restitution view accepts the reality of conflict but does not conceive of this as grounding a right to compensation for the failure to discharge some continuing duty. Rather, the conflict of duty triggers a new duty, namely the professional duty to re-establish a trusting relationship with the patient. The view explains how conflicts of duty can generate circumstances where patients feel that the equality of the relation is threatened and they may also sense a gap between their and the professional's understanding of the situation. These circumstances call for measures that enable trust to be regained, but that does not imply that trust has been betrayed. Even a professional loyal to the fiduciary relation may be faced with the need to make a decision that undermines legitimate patient expectations. Responding to this decision with deep stings of conscience and a desire to compensate reveals lack of commitment to the decision, whereas an ambition to restitute the relation expresses continued loyalty to the patient's interests.

\section{Acknowledgments}

The paper has benefited from the peer review, feedback at the 2017 Conference for the Norwegian Network of Professional Ethics, and discussion at the Counterfactual Union in Oslo.

\section{References}

1. $₫$ Searle JR. What is an institution? J Inst Econ 1999;1(1):122.doi:10.1017/S1744137405000020

2. $₫$ Tännsjö T. Context-Dependent preferences and the right to forgo life-saving treatments. Soc Theory Pract2015;41(3):716-33.doi:10.5840/soctheorpract201541438

3. $\unlhd$ Radzik L. On minding your own business: differentiating accountability relations within the moral community. Soc Theory Pract 2011;37(2):574-98.

4. $₫$ Wallace RJ. Reasons, relations, and commands: reflections on Darwall. Ethics 2007;118(1):24-36.doi:10.1086/522016

5. $₫ \quad$ Beauchamp TL, Childress JF. Principles of biomedical ethics. Oxford University Press: Oxford, 2009.

6. $\Perp$ Raz J. Practical reason and norms. London: Hutchinson, 1975:26.

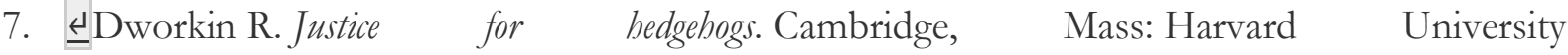
Press, 2011.doi:10.1111/j.1467-8519.2005.00438.x

8. $₫$ Ross WD. The right and the good. Oxford: Oxford University Press, 1930:21.doi:10.2307/2940917

9. $₫$ Hardimon MO. Hegel's social philosophy. Cambridge: Cambridge University Press:89.

10. $\Perp$ Beste J. Instilling hope and respecting patient autonomy: reconciling apparently conflicting duties. Bioethics2005;19:215-31.

11. $₫$ Cassell EJ. The principles of the Belmont report revisited. Hastings Cent Rep 2000;30(2):1221.

12. $₫$ Grice P. Logic and conversation. In: Cole P, Morgan J, eds. Syntax and semantics, 3: speech acts. New York: Academic Press.

13. $₫$ Calhoun C. Standing for something. J Philos 1995;92(2):235-60.

14. $\Perp$ Scherkoske G. Integrity and the virtues of reason. Cambridge: Cambridge University Press:129. 